\title{
TAGUCHI OPTIMIZATION AND EXPERIMENTAL INVESTIGATION OF THE PENETRATION RATE OF COMPACT POLYCRYSTALLINE DIAMOND DRILLING BITS IN CALCAREOUS ROCKS
}

\author{
Abdelkader Khentout ${ }^{1 *}$, Mohamed Kezzar ${ }^{1}$, Lakhdar Khochemane $^{1}$ \\ ${ }^{1}$ Mechanical Engineering Department, University of 20 Août 1955 Skikda, El Hadaiek Road, B. O. 26, \\ 21000 Skikda, Algeria
}

(Received: July 2018 / Revised: November 2018 / Accepted: January 2019)

\begin{abstract}
In the field of drilling there is increasing interest in topics such as degradation of drilling tools and estimation of penetration speed, as well as efforts to optimize geometrical parameters and drilling processes. The current study was based on an original experimental setup that estimates the actual operating conditions of drilling tools and proposed mathematical models with and without interactions. These models characterize the penetration speed of a widely used compact polycrystalline diamond (PDC) oil-drilling bit. The special focus of this study was on the cutter penetration bit, with the aim of investigating the influence of four operating variables weight on bit (WOB), bit rotational speed (RPM), cutting angle $\beta$, and compressive strength Cs on yield maximum penetration rate, using Taguchi's design-of-experiment concepts. In the study, 27 experimental runs based on Taguchi's $\mathrm{L}_{27}$ orthogonal array were performed with signal to-noise $(\mathrm{S} / \mathrm{N})$ ratio, analysis of variance (ANOVA), and regression analysis being used, with penetration rate as response variables. From the optimization and experimental analyses conducted, it was observed that $\mathrm{WOB}_{3}(160 \mathrm{kgf}), \mathrm{RPM}_{3}(152 \mathrm{rpm}), \beta_{3}\left(45^{\circ}\right)$, and $\mathrm{Cs}_{1}(640$ $\mathrm{kgf} / \mathrm{cm}^{2}$ ) had significant influence on penetration rate. The optimal values obtained during the study optimization using the Taguchi approach were validated by confirmation experiments.
\end{abstract}

Keywords: ANOVA analysis; Drilling bit; Penetration rate; Signal-to-noise; Taguchi

\section{INTRODUCTION}

Drilling plays a vital role in oil and gas exploration and production around the world. Drilling efficiency is linked to the additional costs involved in using a platform, which can reach several hundreds of thousands of dollars a day (Wang et al., 2012). One of the most important parameters in planning drilling operations and the estimation of cost is the penetration rate (ROP) (Bilgin et al., 2003), this depending on operational variables including controllable parameters, such as operational variables, bit type, diameter, weight, and rotational speed, as well as rock properties and geological conditions (Moeni et al., 2014).

Drill-bit design is one of the factors that affects ROP during drilling (Gerbaud et al., 2011), and so the drilling industry and research community carry out continuous research into drill-bit design to improve overall drilling performance and reduce drilling costs and thus to increase margins. The choice of bit depends on several factors, one of which is whether the formation to be drilled is hard, soft, medium hard or medium soft (Moeni et al., 2014).

\footnotetext{
*Corresponding author's email: khentoutabdou@yahoo.com, Tel. +213-6677-00204, Fax. +213-3897-4238 Permalink/DOI: https://doi.org/10.14716/ijtech.v10i2.2137
} 
A PDC bit is a drilling tool that uses polycrystalline diamond compact cutters to shear rock formations using a continuous scraping motion. The introduction of PDC in 1973 facilitated the development of the first drill bit that used synthetic diamonds as cutting elements (Kerr et al., 1988). Through continuous research and development over the last decade, PDC drill-bit performance has been improved by innovation in PDC wear, impact resistance, and better understanding of vibration. According to Kerr et al. (1988), there are three main design features affecting PDC drill-bit performance: the number of blades with cutters, cutter edge geometry and the diameter of cutters. In planning an efficient drilling operation, it is essential to learn how all these parameters influence the penetration rate.

In 1960, Taguchi proposed an effective statistical technique based on experimental data (Antony, 2006) and designed to involve tolerance and parameters in design (Taguchi, 1987; Taguchi, 1993). In contrast to previous experimental techniques, Taguchi's developed technique takes into consideration the effects of several factors. To enhance response quality by using only a few experimental data, the Taguchi method has been used to design an orthogonal array which includes S/N ratio, noise, and controlled factors (Phadke, 1989; Ross, 1996; Fotis et al., 2008; Venkateswarlu et al., 2010; Celik, 2010). Up until now, this method has been used for drilling-parameter optimization with considerable success (Changheon et al., 2017; Derdour et al., 2017; Rais et al., 2017; Derdour et al., 2018).

This experimental study was carried out by applying Taguchi methodology to provide complete information on all factors impacting on the performance parameters, such as cutting angle, WOB, rotation speed and compressive strength. From these experiments, it is possible to determine the drilling parameters that give a maximum penetration rate.

\section{EXPERIMENTAL DETAILS}

\subsection{Laboratory Investigation}

\subsubsection{Tools and equipment}

In this investigation, three types of sedimentary (limestone and marble) rocks were collected from different localities in Algeria reflecting variety of hardness. During sample collection, each block was inspected for macroscopic defects, to ensure use of test specimens free of fractures. Penetration rate of drill-bit setup was carried out for the three different rock samples. The blocks were approximately $30 \mathrm{~cm} \times 30 \mathrm{~cm} \times 4 \mathrm{~cm}$ in size.

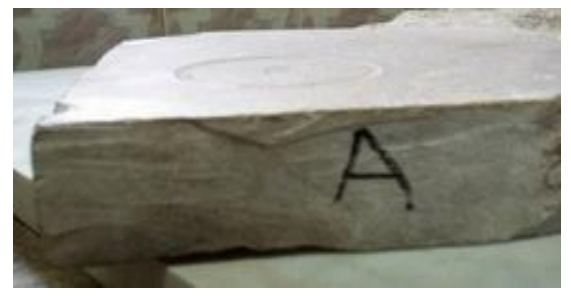

Figure 1 Rock A from the quarry of ENOF unit, El Ghedir

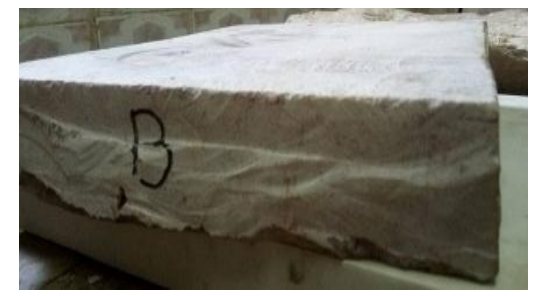

Figure 2 Rock B from the quarry of Hadjar Soud

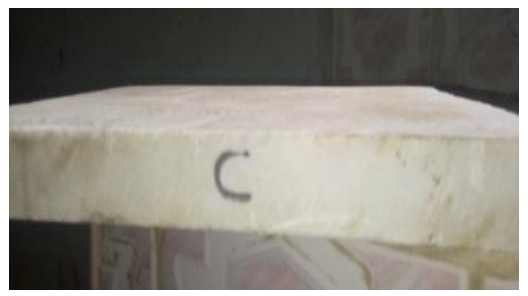

Figure 3 Rock $\mathrm{C}$ from the Felfla quarry

In this study, the experiments were carried out using a specially designed vertical drill rig to measure ROP in a simulation of the rotary drilling process. The drill bits used were PDC cylinder cutters in which cutting angle was varied between $3^{\circ}, 8^{\circ}$ and $45^{\circ}$. During drilling, ROP was measured for different sedimentary rocks at different WOBs and RPMs. 
Table 1 Properties of the drilling bit rig

\begin{tabular}{lr}
\hline \multicolumn{2}{c}{ Drilling Properties } \\
\hline Maximum power output of the motor & $1.5 \mathrm{kw}$ \\
Maximum bit weight & $250 \mathrm{kgf}$ \\
Maximum rotary speed & $220 \mathrm{rpm}$ \\
Bit diameter & $13 \mathrm{~mm}$ \\
\hline
\end{tabular}

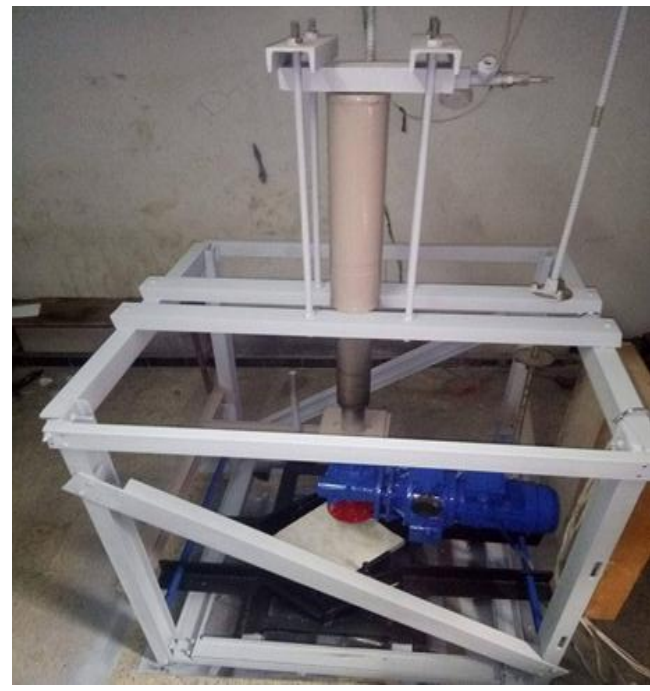

Figure 4 Experimental drilling rig

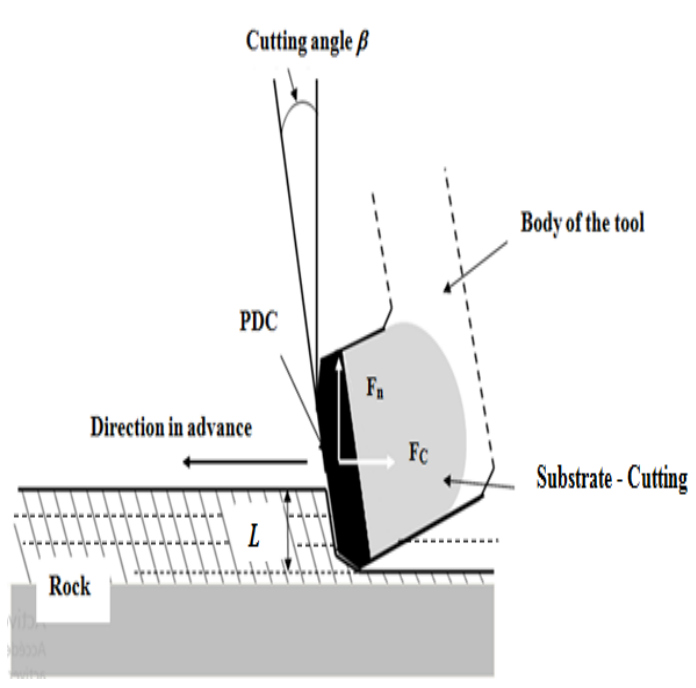

Figure 5 Construction of a PDC cutter

\subsection{Determination of Rock Properties}

Compressive strength is determined by placing a sample on the table of a hydraulic press, then applying a charge until total crushing of the sample is achieved. Resistance is then calculated using the following formula (Khochemane, 1990):

$$
C s=\frac{F}{S} ; k g f / \mathrm{cm}^{2}
$$

Table 2 Compressive strength of the rocks

\begin{tabular}{cc}
\hline Rocks & Compressive strength \\
\hline Rock A & $1550 \mathrm{kgf} / \mathrm{cm}^{2}$ \\
Rock B & $750 \mathrm{kgf} / \mathrm{cm}^{2}$ \\
Rock C & $640 \mathrm{kgf} / \mathrm{cm}^{2}$ \\
\hline
\end{tabular}

\subsection{Plan of Investigation}

In this study, the drilling experiments are planned based on Taguchi experimental design. A Taguchi $\mathrm{L}_{27}$ orthogonal array is used to discover the influence of various control parameters, such as cutting angle $(\beta)$, WOB, RPM, and compressive strength $(\mathrm{Cs})$ on penetration rate developed during drilling. In this study, three levels and three factors are considered, as presented in Table 3. 
Table 3 Factors and levels selected

\begin{tabular}{lccccc}
\hline \multirow{2}{*}{ Factors } & \multirow{2}{*}{ Unit } & \multirow{2}{*}{ Code } & \multicolumn{3}{c}{ Levels } \\
\cline { 4 - 6 } & & & 1 & 2 & 3 \\
\hline Cutting angle & Degree & $\beta$ & 3 & 8 & 45 \\
Weight on bit & $\mathrm{kgf}$ & WOB & 80 & 120 & 160 \\
Rotation speed & $\mathrm{rpm}$ & $\mathrm{RPM}$ & 118 & 135 & 152 \\
Compressive strength & $\mathrm{kgf} / \mathrm{cm}^{2}$ & $\mathrm{Cs}$ & 640 & 750 & 1550 \\
\hline
\end{tabular}

\section{METHOD OF ANALYSIS}

\subsection{Taguchi Technique}

Taguchi developed a special design of orthogonal arrays that can be used to study the entire parameter space with only a small number of experiments. A statistical scale called signal-tonoise $(\mathrm{S} / \mathrm{N})$ ratio was used to analyze the test results, because this ratio represents both the mean and the variation (dispersion) of the experimental results in this method. The underlying principle is to use basic data obtained from experiments together with knowledge, in the form of orthogonal matrices of the $\mathrm{S} / \mathrm{N}$ ratios in $\mathrm{dB}$, to represent and evaluate a response to a quality or a characteristic, with the largest $\mathrm{S} / \mathrm{N}$ ratio being the required response (Celik, 2010; Periyanan et al., 2011; Kang \& Hadfield, 2015). There are three categories used in S/N ratio analysis techniques, namely smaller-the-better, nominal-the-best, and larger-the-better. Largerthe-better is used where a higher value is desired, as shown by Equation 2:

Larger-the-better is used where a higher value is desired:

$$
S / N \text { ratio }(\eta)=-10 \log _{10} \frac{1}{n} \sum_{i-1}^{n} \frac{1}{y_{i}^{2}}
$$

Smaller-the-better is used where a lower value is desired:

$$
S / N \text { ratio }(\eta)=-10 \log _{10} \frac{1}{n} \sum_{i=1}^{n} y_{i}^{2}
$$

Nominal-the-best is used where a minimum value is desired:

$$
S / N \text { ratio }(\eta)=-10 \log _{10} \frac{1}{n} \frac{\mu^{2}}{\sigma^{2}}
$$

where $\mathrm{i}=1,2, \ldots \mathrm{n}, \mu$ is mean, $\sigma$ is variance and $\mathrm{y}_{\mathrm{i}}$ is the response value for an experimental condition (Vellaiyan et al, 2018).

The $\mathrm{S} / \mathrm{N}$ ratio for each level of the process parameters was calculated based on $\mathrm{S} / \mathrm{N}$ analysis. Regardless of the quality characteristic category, the highest results among the $\mathrm{S} / \mathrm{N}$ ratios correspond to a better-quality characteristic and therefore the optimal level for process parameters is the level with the highest S/N ratio (Periyanan et al., 2011; Shafee et al., 2014).

\subsection{Experimental Plan}

The design of the experiment is an important factor in carrying out the tests using the available means. The Taguchi table was chosen because of the minimum number of experimental tests needed; it is more efficient when using many variable factors than full factorial designs (Taguchi, 1993) or fractional factorial designs. In addition, $L_{27}$ was chosen to increase the accuracy of the test, is shown in Table 4.

The experimental matrix is composed of four columns, corresponding to the selected factors, and 27 lines, representing the series of rotary drilling experiments carried out. In the last two 
columns, the experimental values of the penetration rate and their calculated $\mathrm{S} / \mathrm{N}$ ratios are reported. The signal noise of the penetration rate is calculated with the Equation 2 to maximize the penetration rate, while the penetration rate is determined by the Equation 5 (Derdour et al., 2017):

$$
R O P=L / t_{d} ; m m / s
$$

where $L$ is the depth of the drill bit and $t_{d}$ is the time taken in the drilling process, identified to eight seconds in these experiments.

Table 4 Taguchi's L27 orthogonal array

\begin{tabular}{|c|c|c|c|c|c|c|c|c|c|c|c|c|c|}
\hline Tests & $\beta$ & WOB & RPM & Cs & ROP & $(\mathrm{S} / \mathrm{N})$ & Tests & $\beta$ & WOB & RPM & Cs & $\operatorname{Pr}$ & $(\mathrm{S} / \mathrm{N})$ \\
\hline 1 & 3 & 80 & 118 & 640 & 0.71 & -2.9748 & 15 & 8 & 120 & 152 & 640 & 2.53 & 8.0624 \\
\hline 2 & 3 & 80 & 135 & 750 & 0.95 & -0.4455 & 16 & 8 & 160 & 118 & 1550 & 1.17 & 1.3637 \\
\hline 3 & 3 & 80 & 152 & 1550 & 0.28 & -11.0568 & 17 & 8 & 160 & 135 & 640 & 2.82 & 9.0050 \\
\hline 4 & 3 & 120 & 118 & 750 & 1.01 & 0.0864 & 18 & 8 & 160 & 152 & 750 & 2.91 & 9.2779 \\
\hline 5 & 3 & 120 & 135 & 1550 & 0.49 & -6.1961 & 19 & 45 & 80 & 118 & 640 & 0.96 & -0.3546 \\
\hline 6 & 3 & 120 & 152 & 640 & 2.01 & 6.0639 & 20 & 45 & 80 & 135 & 750 & 1.60 & 4.0824 \\
\hline 7 & 3 & 160 & 118 & 1550 & 1.48 & 3.4052 & 21 & 45 & 80 & 152 & 1550 & 1.13 & 1.0616 \\
\hline 8 & 3 & 160 & 135 & 640 & 2.02 & 6.1070 & 22 & 45 & 120 & 118 & 750 & 1.43 & 3.1067 \\
\hline 9 & 3 & 160 & 152 & 750 & 1.92 & 5.6660 & 23 & 45 & 120 & 135 & 1550 & 1.71 & 4.6599 \\
\hline 10 & 8 & 80 & 118 & 640 & 1.32 & 2.4115 & 24 & 45 & 120 & 152 & 640 & 3.02 & 9.6001 \\
\hline 11 & 8 & 80 & 135 & 750 & 1.43 & 3.1067 & 25 & 45 & 160 & 118 & 1550 & 1.61 & 4.1365 \\
\hline 12 & 8 & 80 & 152 & 1550 & 0.80 & -1.9382 & 26 & 45 & 160 & 135 & 640 & 3.01 & 9.5713 \\
\hline 13 & 8 & 120 & 118 & 750 & 1.29 & 2.2118 & 27 & 45 & 160 & 152 & 750 & 3.34 & 10.4749 \\
\hline 14 & 8 & 120 & 135 & 1550 & 1.49 & 3.4637 & & & & & & & \\
\hline
\end{tabular}

\section{RESULTS AND DISCUSSION}

\subsection{Analysis of $\mathrm{S} / \mathrm{N}$ Ratio}

Figure 6 shows the effects of the source factors on the mean values of the penetration rate, any increases in the drilling operational parameters, and the geometric parameters of the drill bits (WOB, RPM, and $\beta$, respectively) that should lead in principle to increased penetration rate. In contrast, any increase of $\mathrm{Cs}$ causes deceleration of the penetration rate.

Table 5 Responses for $\mathrm{S} / \mathrm{N}$ ratios based on larger-is-better assumption

\begin{tabular}{ccccc}
\hline Level & $\beta$ & WOB & RPM & Cs \\
\hline 1 & 0.07282 & -0.67865 & 1.48805 & 5.27688 \\
2 & 4.10717 & 3.45100 & 3.70606 & 4.17415 \\
3 & 5.14877 & 6.55640 & 4.13465 & -0.12227 \\
Delta & 5.07596 & 7.23505 & 2.64659 & 5.39915 \\
Rank & 3 & 1 & 4 & 2 \\
\hline
\end{tabular}

The optimum levels of the means of $\mathrm{S} / \mathrm{N}$ ratios of the ROP values at all factors and levels are given in Table 5. The highest $\mathrm{S} / \mathrm{N}$ ratio specified for each factor provides the best experimental result, namely the experimental result with the maximum penetration rate. The average $\mathrm{S} / \mathrm{N}$ ratios corresponding to each level of control factors for penetration rate are given in Figure 6. 


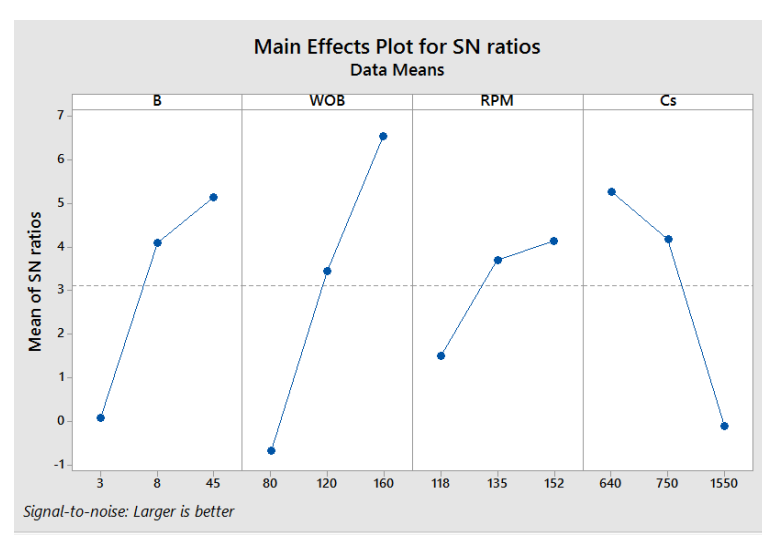

Figure 6 Main factor effects plot for $\mathrm{S} / \mathrm{N}$ ratios on penetration rate $(\mathrm{ROP})$

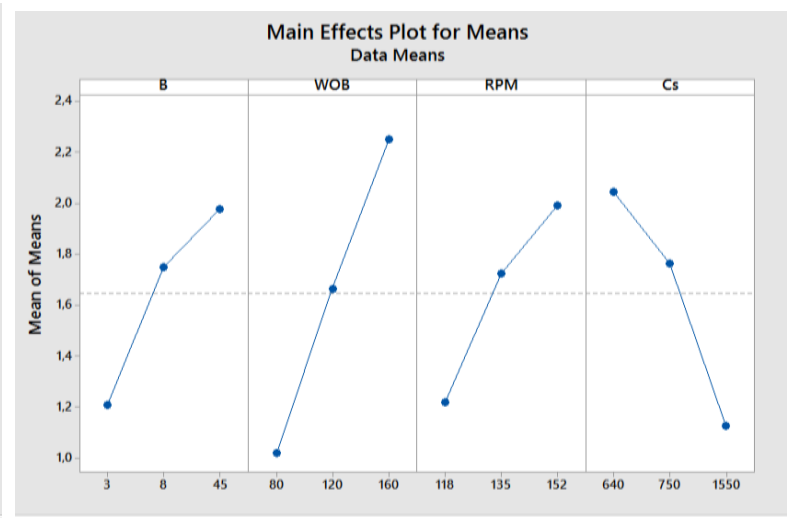

Figure 7 Main factor effects for means on penetration rate $(\mathrm{ROP})$

In Figure 6, the highest $\mathrm{S} / \mathrm{N}$ ratios demonstrate a significant impact of the parameter on the penetration rate. Under these experimental conditions, the results obtained (see Table 5 and Figure 7) show that the effects of WOB and Cs on the penetration rate are greater than those of RPM and $\beta$.

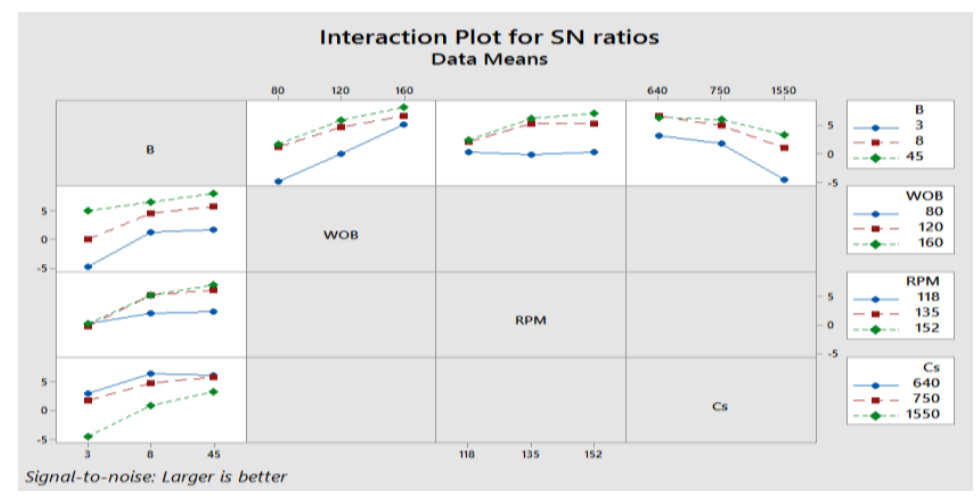

Figure 8 Interaction plots for penetration rate for all factors

Figure 8 shows the interaction for $\mathrm{S} / \mathrm{N}$ ratios between the source factors and their effects on the penetration rate. These optimum control factors for obtaining a maximum penetration rate involve the following combination of experimental factors: $\beta_{3} \mathrm{WOB}_{3} \mathrm{RPM}_{3} \mathrm{Cs}_{1}$, where $\beta_{3}=45^{\circ}$; $\mathrm{WOB}_{3}=160 \mathrm{kgf} ; \mathrm{RPM}_{3}=152 \mathrm{rpm} ;$ and $\mathrm{Cs}_{1}=640 \mathrm{kgf} / \mathrm{cm}^{2}$, as presented in Table 6.

Table 6 Optimal parameters for the drilling bit

\begin{tabular}{ccccc}
\hline Factor (level) & $\beta_{3}$ & $\mathrm{WOB}_{3}$ & $\mathrm{Rpm}_{3}$ & $\mathrm{Cs}_{1}$ \\
\hline Value & 45 & 160 & 152 & 640 \\
$\mathrm{~S} / \mathrm{N}$ & 5.14877 & 6.55640 & 4.13465 & 5.27688 \\
Rank & 3 & 1 & 4 & 2 \\
\hline
\end{tabular}

\subsection{ANOVA Pareto Analysis}

Statistical analysis of the obtained results was performed using the ANOVA Pareto method, due to its simplicity and effectiveness. It is also quick to use and does not need to be tested by the Fisher method (Derdour et al., 2017). ANOVA Pareto analysis enables determination of the percentage of the most important parameters and also confirms information on prevalence and effect, appropriate here because the most important parameters in this experiment were already 
known. In the current work, the ANOVA Pareto method has been used with the $\mathrm{S} / \mathrm{N}$ ratio in order to simplify the obtained results and summarize them, as presented in Table 7. Sum of the squares of the differences (S) for each factor are also shown (Hamdan et al., 2012). Table 7 shows the initial statistical analysis using the ANOVA Pareto method.

Table 7 Analysis of variance (ANOVA Pareto) of drilling

\begin{tabular}{ccccc}
\hline Level & $\beta$ & WOB & RPM & Cs \\
\hline 1 & 0.07282 & -0.67865 & 1.48805 & 5.27688 \\
2 & 4.10717 & 3.45100 & 3.70606 & 4.17415 \\
3 & 5.14877 & 6.55640 & 4.13465 & -0.12227 \\
Sum of squares of differences (S) & 43.126 & 79.0434 & 12.1075 & 48.826 \\
Contribution ratio (\%) & 23.552 & 43.168 & 6.612 & 26.665 \\
Rank & 3 & 1 & 4 & 2 \\
Cumulative contribution ratio & 93.385 & 43.168 & 100 & 69.833 \\
\hline
\end{tabular}

\subsection{Development of Mathematical Model}

A quadratic regression model was developed for penetration rate (ROP) based on experimental results using MINITAB software, Version 16. The model helped to predict the response as a function of independent variables and their interactions. A second-order response surface model equation is as follows:

$$
Y=b_{\mathrm{O}}+\sum_{i=1}^{n} b_{i} x_{i u}+\sum_{i}^{n} b_{i i} x_{i u}^{2}+\underbrace{n}_{\substack{i=1 \\ i \prec j}} b_{i j} x_{i u} x_{j u}+\varepsilon
$$

In the mathematical model (Equation 6), Y represents the response $x_{i u}$ while $x_{j u}$ are the input parameters (factors), $b_{0}$ is the constant of the regression equation, $b_{i}$ are the linear coefficients, $b_{i i}$ are the quadratic coefficients, $b_{i j}$ are the interaction coefficients, and $\varepsilon$ is the fitting error (Montgomery et al., 2001; Wang et al., 2007; Tetteh et al., 2018).

The coefficients of the model for the corresponding response are estimated using the regression analysis technique for level of significance $\alpha=5 \%$, and level of confidence of $95 \%$.

The expected final model for the penetration rate is:

$$
\begin{gathered}
\mathrm{ROP}=-8.41+0.0612 \beta+0.0084 \mathrm{WOB}+0.1506 \mathrm{RPM}-0.00641 \mathrm{Cs}-0.002441 \beta \times \beta \\
-0.000017 \mathrm{WOB} \times \mathrm{WOB}-0.000481 \mathrm{RPM} \times \mathrm{RPM}+0.000002 \mathrm{Cs} \times \mathrm{Cs}+0.000088 \beta \times \mathrm{WOB} \\
+0.000464 \beta \times \mathrm{RPM}+0.000001 \beta \times \mathrm{Cs}+0.000010 \mathrm{WOB} \times \mathrm{Cs}
\end{gathered}
$$

The results of the analysis of the variance of the penetration rate (Table 8 ) show that $\beta \times \beta$ is the interaction having the greatest effect on the total variation of the penetration rate, contributing $31.55 \%$. The second greatest effect on the penetration rate is the interaction $\beta \times \mathrm{RPM}$, with a contribution of $12.11 \%$, followed by compressive strength $\mathrm{Cs}$ and interaction $\mathrm{WOB} \times \mathrm{Cs}$, with contributions of $9.41 \%$ and $6.87 \%$, respectively. In contrast, the factor RPM, $\beta$ and the interactions $\mathrm{Cs} \times \mathrm{Cs}, \mathrm{RPM} \times \mathrm{RPM}$, and $\beta \times \mathrm{WOB}$ have very low contributions to the variation in penetration rate of $4.68 \%, 4.34 \%, 4.44 \%, 3.53 \%$, and $2.40 \%$. The WOB, (at $0.52 \%$ ), and the interactions $\mathrm{WOB} \times \mathrm{WOB}(0.14 \%)$ and $\beta \times \mathrm{Cs}(0.06 \%)$ do not have significant effects on the total variability of penetration rate. 
Table 8 ANOVA results for penetration rate (ROP)

\begin{tabular}{lcccccc}
\hline \multicolumn{1}{c}{ Source } & DF & AdjSS & AdjMS & F-Value & P-Value & $\mathrm{P}_{\mathrm{C}} \%$ \\
\hline Regression & 12 & 17.1073 & 1.42561 & 30.81 & 0.000 & $/$ \\
$\beta$ & 1 & 0.1410 & 0.14096 & 3.05 & 0.103 & 4.34 \\
WOB & 1 & 0.0168 & 0.01682 & 0.36 & 0.556 & 0.52 \\
RPM & 1 & 0.1522 & 0.15219 & 3.29 & 0.091 & 4.68 \\
Cs & 1 & 0.3058 & 0.30582 & 6.61 & 0.022 & 9.41 \\
$\beta \times \beta$ & 1 & 1.0250 & 1.02497 & 22.15 & 0.000 & 31.55 \\
WOB $\times$ WOB & 1 & 0.0046 & 0.00463 & 0.10 & 0.756 & 0.14 \\
RPM $\times$ RPM & 1 & 0.1147 & 0.11475 & 2.48 & 0.138 & 3.53 \\
Cs $\times$ Cs & 1 & 0.1444 & 0.14437 & 3.12 & 0.099 & 4.44 \\
$\beta \times$ WOB & 1 & 0.0780 & 0.07796 & 1.69 & 0.215 & 2.40 \\
$\beta \times R P M$ & 1 & 0.3933 & 0.39329 & 8.50 & 0.011 & 12.11 \\
$\beta \times$ Cs & 1 & 0.0019 & 0.00193 & 0.04 & 0.841 & 0.06 \\
WOB $\times$ Cs & 1 & 0.2233 & 0.22326 & 4.83 & 0.045 & 6.87 \\
Error & 14 & 0.6477 & 0.04627 & & & \\
Total & 26 & 17.7551 & & & & \\
\hline
\end{tabular}

Figure 9 show the relationships between actual and predicted response values for ROP. The presented quadratic regression model provided a very good statistical performance with high correlation coefficients of 0.9635 between the actual and predicted values of the penetration rate.

Finally, as shown in Figure 10, for normal probability of the residuals of the penetration rate model, it is found that the residuals are in a reasonably straight line, which may lead to the conclusion that the errors have a normal distribution. As a consequence, the penetration rate model is significant.

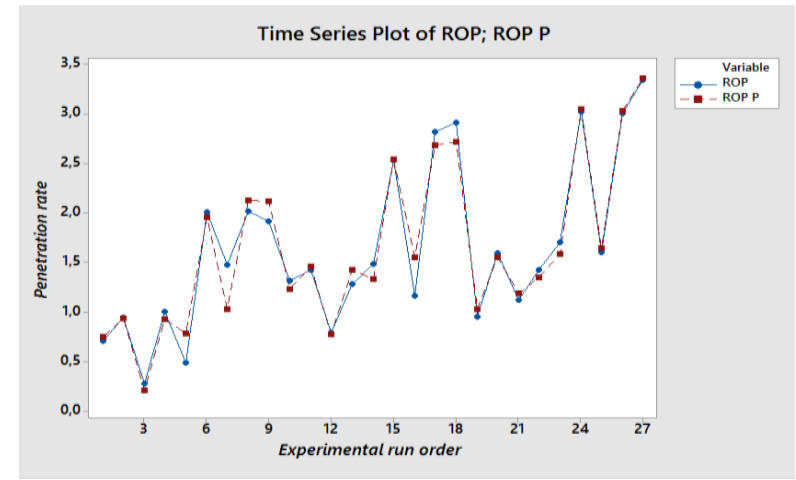

Figure 9 Experimental values and predicted values of penetration rate $(\mathrm{ROP})$

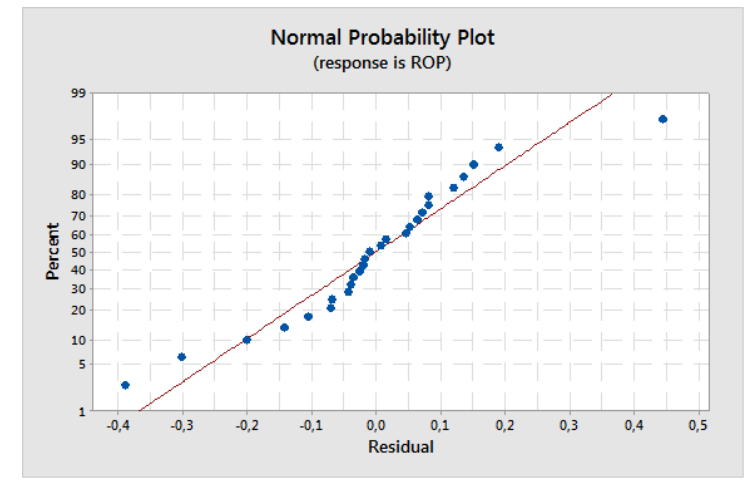

Figure 10 Potential normal distribution plot of the residuals for penetration rate $(\mathrm{ROP})$

\subsection{Validation of Experiment}

A confirmation experiment was performed with optimal level result of $3.48 \mathrm{~mm} / \mathrm{s}$. Table 9 shows the error difference between the predicted and experimental responses. It can be observed that for reliable statistical analysis, error values should be less than $20 \%$ (Cetin et al., 2011), so error percentages are within acceptable limits. Therefore, it can be deduced that the proposed empirical model can successfully predict ROP during drilling process.

Table 9 error difference between the predicted and experimental responses

\begin{tabular}{cccc}
\hline Penetration rate & Taguchi & Experimental & Error \% \\
\hline Initial $\mathrm{A}_{1} \mathrm{~B}_{1} \mathrm{C}_{1} \mathrm{D}_{1}$ & 0.877778 & 0.71 & 19.11 \\
\hline Optimal $\mathrm{A}_{3} \mathrm{~B}_{3} \mathrm{C}_{3} \mathrm{D}_{1}$ & 3.52222 & 3.48 & 1.20 \\
\hline
\end{tabular}




\section{CONCLUSION}

In this study, the Taguchi technique is used to obtain optimal drilling parameters in the drilling of different rocks under dry conditions. The experimental results were evaluated using $\mathrm{S} / \mathrm{N}$ ratio, Pareto variance analysis, and regression analysis.

The following conclusions can be drawn: (1) As a result of the Taguchi experimental it was found that the interactions $\beta \times \beta$ and $\beta \times \mathrm{RPM}$ were the most significant factors affecting the penetration rate, with percentage contribution of $31.55 \%$ and $12.11 \%$, respectively; (2) The optimum control factors for penetration rate $\beta_{3} \mathrm{WOB}_{3} \mathrm{RPM}_{3} \mathrm{Cs}_{1}$ were $\beta_{3}=45^{\circ}, \mathrm{WOB}_{3}=160 \mathrm{kgf}$, $\mathrm{RPM}_{3}=152 \mathrm{rpm}$, and $\mathrm{Cs}_{1}=640 \mathrm{kgf} / \mathrm{cm}^{2}$; (3) ANOVA Pareto analysis showed that WOB and Cs have positive effects on penetration rate; (4) The quadratic mathematical model is developed with a confidence interval of 96.35 for the prediction of penetration rate (ROP).

In this study, the Taguchi technique was successfully applied both to determining the optimal combinations of drilling parameters and also to minimize costs and the number of drilling experiments.

\section{REFERENCES}

Antony, J., 2006. Taguchi or Classical Design of Experiments: A Perspective from a Practitioner. Sensor Review, Volume 26, pp. 227-230

Bilgin, A., Yalçin, E., Kutbay, H.G., Kilinc, M., 2003. Nutrient Concentrations and Biomass in Lake Vegetation and Nutrient Limitation in Lakes of Northern Black Sea Region of Turkey. Ekológia (Bratislava), Volume 22(3), pp. 257-268

Celik, L., 2010. Monitoring Vibration in Grinding Process and Regression Modeling of Surface Roughness. M.S. Master's Thesis, Selçuk University, Turkey

Cetin, M.H., Ozcelik, B., Kuram, E., Demirbas, E., 2011. Evaluation of Vegetable Based Cutting Fluids with Extreme Pressure and Cutting Parameters in Turning of AISI 304L by Taguchi Method. Journal of Cleaner Production, Volume 19(17-18), pp. 2049-2056

Changheon, S., Jintai, C., Kim, J.H., Oh, J.Y., 2017. Design Optimization of a Drifter using the Taguchi Method for Efficient Percussion Drilling. Journal of Mechanical Science and Technology, Volume 31(4), pp. 1797-1803

Derdour, F., Kezzar, M., Bennis, O., Khochemane, L., 2017. The Optimization of the Operational Parameters of a Rotary Percussive Drilling Machine using the Taguchi Method. World Journal of Engineering, Volume 15(3), pp. 62-69

Derdour, F., Kezzar, M., Khochemane, L., 2018. Optimization of Penetration Rate in Rotary Percussive Drilling using Two Techniques: Taguchi Analysis and Response Surface Methodology (RMS). Powder Technology Journal, Volume 339, pp. 846-853

Fotis, S., Besseris, G., Alafodimos, K., 2008. Application of Taguchi's Experimental Design Methodology for Product Optimization in Food Engineering Mixtures. Proceedings $3^{\text {rd }}$ International Scientific Conference (ERA-3), Aegina, Greece

Gerbaud, L., Menand, S., Sellami, H., 2011. PDC Bits: All Comes from the Cutter Rock Interaction In: IADC/SPE Drilling Conference. Miami, Florida, USA

Hamdan, A., Sarhan, A.A.D., Hamdi, M., 2012. An Optimization Method of the Machining Parameters in High-speed Machining of Stainless Steel using Coated Carbide Tool for Best Surface Finish. The International Journal of Advanced Manufacturing Technology, Volume 58(1-4), pp. 81-91

Kang, J., Hadfield, M., 2015. Parameter Optimization by Taguchi Methods for Finishing Advanced Ceramic Balls using a Novel Eccentric Lapping Machine. Proceeding Institution Mechanical Engineers, Volume 215 (B), pp. 69-78 
Kerr, C.J., 1988. PDC Drill Bit Design and Field Application Evolution. Journal of Petroleum Technology, Volume 40(3), pp. 327-332

Khochemane, L., 1990. Augmentation de l'Efficacité Technique d'Utilisation des Machines de Forage Rotatif a Taillant Coupant. Master's Thesis, Université d'Annaba, Annaba, Algeria

Moeni, M.J.A., Shaabani. E., Milad, R., 2014. Experimental Evaluation of Hardness Models by Drillability Tests for Carbonate Rocks. Journal of Petroleum Science and Engineering, Volume 113, pp. 104-108

Montgomery, D.C., 2001. Design and Analysis of Experiments. $8^{\text {th }}$ Edition, Arizona State University

Periyanan, P.R., Natarajan, U., Yang, S.H., 2011. A Study on the Machining Parameters Optimization of Micro-end Milling Process. International Journal of Engineering, Science and Technology, Volume 3, pp. 237-246

Phadke, M.S., 1989. Quality Engineering using Robust Design. Prentice Hall, Englewood Cliffs, New Jersey

Rais, K., Kara, M., Gadri, L., Hadji, R., Khochman, L., 2017. Original Approach for the Drilling Process Optimization in Open Cast Mines; Case Study of Kef Essenoun Open Pit Mine Northeast of Algeria. Mining Science, Volume 24, pp. 147-159

Ross, P.J., 1996. Taguchi Techniques for Quality Engineering: Loss Function, Orthogonal Experiments, Parameter and Tolerance Design. 2nd Edition, New York, NY: McGraw Hill.

Montgomery, D.C., 2001. Design and Analysis of Experiments. Wiley, Singapore

Shafee, S., Naik, B.B., Sammaiah, K., Mohinoddin, M., 2014. RSW Process Parameters Optimization by Taguchi Method. IOSR Journal of Mechanical and Civil Engineering, Volume 11, pp. 46-54

Taguchi, G., 1987. System of Experimental Design. Unipub/Kraus International Publication, The University of Michigan, Michigan, United State of America

Taguchi, G., 1993. Taguchi on Robust Technology Development-Bringing Quality Engineering Upstream. ASME Press, New York

Taguchi, G., 1993. Taguchi on Robust Technology Development Methods. ASME Press, New York, pp. 1-40

Tetteh, E., Amano, K.O.A., Denis, A.S., Armah, E., 2018. Response Surface Optimisation of Biogas Potential in Codigestion of Miscanthus Fuscus and Cow Dung. International Journal of Technology, Volume (9)5, pp. 944-954

Vellaiyan, S., Amirthagadeswaran, K.S., Sivasamy, D.B., 2018. Taguchi-Grey Relation Based Multi-response Optimization of Diesel Engine Operating Parameters with Water-in-Diesel Emulsion Fuel. International Journal of Technology, Volume (9)1, pp. 68-77

Venkateswarlu, G., Davidson, M.J., Tagore, G.R.N., 2010. Influence of Process Parameters on the Cup Drawing of Aluminium 7075 Sheet. International Journal of Engineering Science and Technology, Volume 2, pp. 41-49

Wang, J.P, Gu, D., Yu, Z., Tan, C., Zhou, L., 2012. A Framework for 3D Model Reconstruction in Reverse Engineering. Computers \& Industrial Engineering, Volume 63(4), pp. 11891200

Wang, J.P., Chen, Y.Z., Ge, X.W., Yu, H.Q., 2007. Optimization of Coagulation-Flocculation Process for a Paper Recycling Wastewater Treatment using Response Surface Methodology. Colloids and Surfaces A: physicochemical and Engineering Aspects, Volume 302(1-3), pp. 204-210 